\title{
Family Planning Targets and Quality of Services: Workers' Perspectives and Dilemmas*
}

\author{
Ruth Simmons and Laura Ghiron
}

This paper uses data from in-depth group interviews with family planning workers in Bangladesh to demonstrate both the dysfunctional influence of family planning targets on quality of care as well as the strong connection between targets and the management system. The findings show that the presence of targets influenced the advice and information workers provided, pushing them towards long-term methods such as sterilisation and the IUD rather than helping clients select metbods most suited to their needs. The paper then shows the connection between the target system and the struc. ture of official and unofficial incentives, the pattern of supervision, the system of accountability and a bierarchically organised and gender-biased organisational culture. The authors argue that unless these underlying managerial determinants of qual. ity of care are addressed, the hope for reaching the goals of the International Conference on Population and Development (ICPD) will remain illusory.

'To understand the most challenging managerial issues requires seeing the whole system that generates the issues.' (Senge)

* The study of female family planning workers upon which this paper is based was designed and implemented in collaboration with Professor Rushikesh Maru who, at the time the data were collected, was Acting Director of the Extension Project of the International centre for Diarrhoeal Diseases Research, Bangladesh. Professor Maru had carefully reviewed these data prior to the time he assumed the directorship of the Indian Institute of Health Management Research in Jaipur in 1996. His sudden death in April 1998 remains incomprehensible. His profound understanding of the field of family planning management inspired the writing of this paper; but its faults are our own.

We gratefully acknowledge Rezina Mita's care and diligence in collecting the data upon which this paper is based, and also wish to thank Shameem Abbassy, Daniel Kabira and Denise Sanderson for research assistance.

Journal of Health Management, 1, 2 (1999)

Sage Publications New Delhi • Thousand Oaks • London 


\section{Introduction}

As part of a global movement to bring about a change towards greater quality of care in family planning programmes, targets for the recruitment of contraceptive acceptors have been widely criticised. For example, Khallil and Myntti (1994) argue that 'quotas have led to abuses in many countries and adversely affect the quality of health care provided since they cause providers to ignore the user's viewpoint, tamper with reproductive rights, and pay little attention to presenting a choice of method, unbiased information, or clinically appropriate services'. India and Bangladesh, two nations in which the target system has been a core component of the national family planning programme, have recently shifted to a target-free approach in an effort to improve overall programme quality. Such a policy shift constitutes an important ingredient of efforts to bring about a greater service orientation in programmes. This paper uses data from in-depth group interviews with family planning workers in Bangladesh to demonstrate both the dysfunctional influence of targets on quality of care in community-based service provision as well as the strong connection between targets and the management system. Including a management perspective in the analysis of targets broadens the understanding of what change is needed in order to build service-oriented programmes. We argue that abolishing targets alone does not suffice. Substantial changes in bureaucratic and management practices are needed if programmes are to obtain improvements in quality of care and assure the respect for reproductive rights to which nations committed themselves at the ICPD in Cairo in 1994.

The data used in this paper are derived from group interviews conducted in 1994 with women employed as community-based outreach workers in the government family planning programme in Bangladesh. Eleven group interviews were undertaken, with a total of 56 Family Welfare Assistants (FWAs). Twenty-six of these had worked in this position for many years; 30 had been recently recruited. Eight of the group interviews were conducted in areas that received technical assistance from the Extension Project of the International Centre for Diarrhoeal Disease Research, Bangladesh, including training and record keeping (for a description of this project see Haaga and Maru [1996] and Phillips et al. [1984]). The remaining three sessions were conducted in comparison areas. ${ }^{1}$

Family planning fieldworkers were responsible for conducting regular household visits with women of reproductive age in their assigned 
work areas, which, at the time of the interviews, consisted of a population of approximately 4,000 people per worker. If fieldwork was conducted regularly, workers could visit each eligible woman once every two months. Workers were responsible for home-based education and distribution of oral contraception, condoms and, in project intervention areas, injectables. Intrauterine devices (IUDs, referred to as Copper T) was available at the nearby subcentre and both sterilisation (tubal ligation) and IUDs at the subdistrict health complex. Fieldworkers were also required to facilitate access to clinic services, accompanying sterilisation or IUD patients at the day of their procedure or taking women with side effects or complications to clinic facilities.

\section{The Effects of the Target System on Contraceptive Choice}

The imperatives laid out by the target system were clearly embedded in the field workers' outlook and this had profound impact on the advice they gave to local women about method choice, one of the central elements of quality of care (Bruce 1990). Most respondents indicated that they discussed the permanent and provider-controlled methods first when they visited women in their local communities, and then slowly progressed to the user-controlled ones. The predominant motive behind this advice was not the women's wishes or circumstances, but the need to fulfil sterilisation and IUD targets. Workers also knew that they had to address women's desires. Given the pressures to meet targets, however, the woman's choice tended to be of secondary importance. In the mind of the worker the very concept of 'choice' had been twisted to suit the logic of targets:

Worker: First of all, you should try for long-term methods. It is well and good if she accepts Copper T, but if she does not like to accept the Copper $\mathrm{T}$ then you will propose injection to her. If she agrees to take injection, it is well and good, but if she does not then you will give her pills or condoms. In this way, you will give her the method of her choice.

Responsiveness to the client occurs within the boundaries of the hierarchy of family planning methods imposed by the demographically 
focused target system. Some workers acknowledged that the client's choice should be paramount. But the target system did not allow them to give priority to client needs:

Moderator: What do you do when a woman says 'Apa (sister), please decide, I do not know the method which I should use?'

Worker 1: In that case we talk about operation and Copper T. But I always explain all the methods to her and she picks up one; then I check her with the screening checklist. If that suits her then I give that and if she gets side effect then I change to a method of my choice if that suits her.

Worker 2: I do the same.

Worker 3: If the woman depends on me then I advise her to do the ligation; if she does not agree then I give her the Copper $T$.

Worker 4: Client's choice is first but because of target pressure we need to push the clients towards our choice.

Workers 1 and 2: Yes, Apa, that is why we do not like targets.

Targets also led to a distortion of information provided about methods. Fieldworkers gave a more favorable representation of the longacting IUD, and discredited other methods, in the following case, the injectable cntraceptive:

Moderator: How much information should women be given before they decide what method to use?

Worker: When we find a baby in her arms then we tell her that if she takes pills then her breast will go dry, if she takes injection then also breast will be dry and monthly menstruation shall stop. If Copper $\mathrm{T}$ is inserted, then it will be better as there is no side effect.

The worker was correct in implying that a breastfeeding woman should not use oral contraceptives containing oestrogen and progestin. However, she was wrong in suggesting that injectables are inappropriate for breastfeeding women (progestin-based injectables can be used six weeks after childbirth in breastfeeding women) and that there are no side effects with the use of the IUD. Providing accurate and balanced information about contraceptive methods is one of the important components of quality of services, but targets undermined the worker's inclination to do so. Instead, targets created incentives to provide biased information, thereby contributing to the extensive 
pattern of misinformation about contraceptive methods that was widespread in these rural areas.

Targets also caused conflict among providers over clients' method choice. Fieldworkers who had been trained in community-based injectable provision were serving a considerable number of injectable clients. They were pleased to have these clients because they found that women were less interested in the IUD and in sterilisation than in the past. The paramedic (Family Welfare Visitor) at the subcentre, by contrast, was trained in IUD provision, had an IUD target and received special incentive payments for every IUD she inserted. As a consequence, she was interested only in providing IUDs and fieldworkers reported that their injectable clients did not receive appropriate care from the paramedic. For example:

Worker 1: Our clients are badly treated by visitors in the subcentre and satellite clinic. We send our clients there for necessary medicines and treatment but instead they get rough behaviour. Afterwards, when we visit our clients after two months in the field, they charge us by saying that we sent them to the subcentre or satellite clinics for treatment but they had received nothing but rough behaviour.

Worker 2: The clients then abuse us. We are also abused by our neighbours. The visitors give more importance to the Copper $\mathrm{T}$ IUD.

Moderator: Why are the Visitors so much interested in the Copper T IUD?

Worker 1: The Visitors show interest in the Copper $T$ because they have a fixed Copper $T$ target to achieve and they get some money per patient. When our pill clients go to them for medicines, they insert the Copper T IUD in them against their will. The clients prefer taking injections to using the Copper $\mathrm{T}$. When we go to see them they scold us severely. They [the women] say, "The important thing is to stop births and it can be done by using any method other than the Copper $\mathrm{T}$ or sterilisation. Why should we use only the Copper T?'

In order to convince women to adopt the Copper $T$, paramedics were reported to give inaccurate information about injectables, saying for example that they 'cause problems with her artery system', or that they are 'likely to make the blood impure'. Such information was 
obviously worrisome to women and tended to lead them to switch methods unnecessarily, or to stop contraceptive use entirely. In one case a worker reported how four of her clients changed to the Copper $\mathrm{T}$ because of such advice, and when they subsequently experienced problems, they switched back to the injectable.

By establishing differential incentives for paramedics and fieldworkers, the targets acted as a barrier for effective cooperation among programme staff. Method choice was distorted and as a consequence women suffered rather than benefited from care.

The requirement to recruit acceptors of IUDs and sterilisation exerted paramount influence on the work style of rural family planning fieldworkers. These patterns of work contrast sharply with the ideals of a client-oriented quality of care approach in which providers have the role of sharing information and helping clients reach a decision that suits their needs and concerns (Ward et al. 1998). In a quality of care-based approach providers do not come to the interaction with an externally imposed criterion for the selection of a contraceptive method. In practice, of course, family planning providers even in the best settings are likely to have biases that may affect interactions with their clients. When method choice is dictated by formalised targets for certain methods, however, the possibility of responding to the client's individual situation is particularly constrained. Moreover, women are put at risk of infection and other harmful consequences when they are subjected to unnecessary medical procedures for the sole reason of meeting a contraceptive targets.

\section{The Impact of Target-focused Supervision}

Most community-based workers experienced intense pressure from their immediate supervisors and programme officers to fulfil targets. ${ }^{2}$ The monthly supervisory meetings consisted of constant reminders to pay attention to targets and included threats that salaries would be withheld unless workers recruited the required number of sterilisation and IUD clients:

Worker 1: You see, I may fail to fulfil my target for sterilisation, but I may exceed the number of injections from four to 10 , or pills from four to 10 , but there is no credit for that, because I could not have that one client targeted for an operation. 
Moderator: Is there any pressure about fulfilling targets? What type of pressure?

Worker 2: Instead of asking about the other family planning methods, I will be asked: 'How many ligations did you bring this month? Why couldn't you bring one single ligation? In that case, you won't receive any pay this month'.

Worker 3: They think we cannot motivate people or do not care to. We just roam around and then take our salary. This is their opinion of us.

Moderator: For how long do they halt your payment?

Worker 1: Until we can get our target of ligation.

Moderator: Then how do you get your salary?

Worker 3: We have to go through a lot of problems.

Moderator: Like what? Please explain.

Worker 2: We pay the clients more, using our own money to motivate them to have ligation.

The message was clear: workers must bring in the specified number of IUD and sterilisation cases or they will not receive their salary on time. Quality of care and a focus on client needs were lost in the process. Under pressure to find sterilisation clients, some workers felt that they had to enlarge the pool of women they contacted with little regard to whether the candidates for the method were appropriate:

I have a fixed target for ligation. I always try to fulfil my target. When pressure will come on me to achieve the target, then I am compelled to procure a client without taking any consideration of her age. Sometimes, we get over-aged women for ligation as we are compelled to do so. We spend a lot of our time in procuring a ligation client.

The impact of targets on the recruitment of older sterilisation clients for whom such a procedure is irrelevant has been reported elsewhere. But it deserves to be reiterated that such procedures are not only irrelevant from a demographic perspective but are harmful interventions, putting women at unnecessary risk for medical complications.

Another respondent provided an example of how she encouraged women to switch from injectables to the IUD in order to do well during a 'Copper T week' when workers were asked to recruit two 
IUD cases, and told that 'efficient' FWAs should recruit more. Eager to be one of the 'efficient' FWAs, she talked at great length to two women, but after spending a long time with them failed to persuade them to have an IUD inserted. At this point it occurred to her that one way of recruiting additional cases might be to convince injectable clients to change to the IUD:

I went to my house. . . when I met a woman who was coming to take the injection. I approached her and started motivating her by saying that she had already taken the injection twice. I suggested the Copper $T$ insertion to her. She did not say yes or no. At last she agreed to accept the Copper T. Then I went to another client who also agreed to my proposal. I thus could convert five clients. The Copper $\mathrm{T}$ was inserted in all of them. It was a wonderful experience in my service life.

In some cases the pressure to produce IUD acceptors led workers to tell outright lies:

Worker 1: Recently, there has been much pressure as regards insertion of Copper T. We are given a target of Copper Ts to achieve at the rate of three to four cases per month. Because of its various side effects, the Copper $\mathrm{T}$ has lost its popularity. Women do not like it any longer. Therefore, when we go to insert it, we do not tell that we are inserting a Copper $T$. We tell our clients that a capsule will be inserted inside the uterus. They are afraid of the Copper T because it causes bleeding. So we tell them that a capsule will be inserted inside the uterus after taking out the Copper T. We also tell that there is a string tied at the top of the capsule that will gradually be dissolved within eight years when cover of the capsule will be taken out. Our clients become convinced on hearing all these false things from us.

Worker 2: We actually insert Copper Ts without their knowledge.

Some respondents acknowledged that these patterns lead to a distortion of services and some argued that such practices serve no purpose:

I know that if I do not get a Copper T IUD client then my salary shall be withheld. Then, moving from one place to another, I 
somehow manage to get a client on the condition that the IUD inserted will be taken out after 10 days. The purpose of doing so is only to save my salary from being withheld. Nobody benefits from such cases.

Or:

We do injustice to our clients of other methods in the matter of timely supplies. Since we do not provide timely supplies to our clients because of our exclusive engagement with recruiting a ligation client, we find that eight or 10 women using the pill have become pregnant. Such pressure is not at all advisable.

Some field workers also reported that supervisors encourage some of these recruitment techniques, and that at times workers felt helpless in the face of pressure from their supervisors to engage in such 'catch-as-catch-can' tactics:

My injection client has lost her husband. Why should she take pills or injections after the death of her husband? The officers insist on her taking pills even now. The client opposes on the plea that she will be criticised by her neighbors if she takes pills now. Finally she did not take anything and nothing had happened. In such circumstances, we have to remain as a silent spectator as we do not get any strength to express our opinions. We do not get any support from our officers in such a situation.

By nature of their position fieldworkers were close to the local population. They knew they could only succeed if they maintained cordial relations with community women. As one woman put it: 'Clients are our gods.' In the above case, the worker knew that a widow who uses oral contraceptives would be subject to intense criticism by her neighbours, and recognised that pressuring clients will not help to build strong relations between herself and the community. Supervisors, by contrast, were not in regular contact with the local community, did not have to recruit acceptors, and their performance rating was not dependent on the goodwill of the local people. As a consequence, they were less sensitive to local opinion than the fieldworker.

The pressure to recruit acceptors of long-term methods had been so intense that it affected workers' perception of what is meant by quality. 
In one group interview, the following dialogue occurred when workers were asked what they understood about the phrase quality of care:

Worker 1: It means a change from one method to another method, that is, from the pill to the injection, or from the injection to the Copper T.

Moderator: Can you explain a bit more?

Worker 2: Say, if one switched from the pill to the injection, which is a better method, and from that to the Copper T followed by ligation...

Moderator: You mean going to a more permanent method?

Worker 2: Right. This is improvement in the quality of method, the quality of services.

Moderator: Do you all agree?

All: Yes.

Moderator: Did you learn this from some training or anyone else? Worker 3: We didn't hear of it formally.

Moderator: Where did you hear of this?

Worker: Sirs [supervisors/officers] discuss this at the meetings.

There was no confusion in the minds of the worker as to what was important to their immediate supervisors and higher level programme officials. What mattered was meeting quotas of new acceptors of a long-acting or permanent method of contraception. A concern for service quality and reproductive rights, by contrast, was not emphasised.

\section{The Managerial Roots of the Target System}

This literature has highlighted the connection of targets to the demographic objectives of the family planning programmes and drawn attention to their deleterious impact on the quality of services (Khallil and Myntti 1994). What has been less clearly understood is that targetbased performance measures and the emphasis on long-acting methods are closely tied to the management practices of complex and resourcepoor public sector bureaucracies. Appreciation of this connection, however, is essential in any effort to improve the overall quality of service delivery in the context of large-scale public sector programmes.

Targets provided the managerial underpinning of the family planning programme in Bangladesh by establishing a mechanism for moti- 
vating staff, for assuring accountability, and for evaluating individuals and programme units. All organisations must communicate a set of goals and objectives to their members and evaluate their performance against these standards. Quantitative sterilisation and IUD targets established performance standards and a mechanism for holding a large staff of workers and supervisors accountable. Some of the workers indirectly recognised this when they stated that they are not against the target system because it provides direction for their work, but they do not like the pressure associated with it.

The interest of the programme in sterilisation and IUDs had two foundations: one demographic, the other bureaucratic or operational. Sterilisation and IUDs are permanent or long-acting methods and therefore of great interest to a demographically-oriented programme. From a bureaucratic or operational perspective these methods are of interest because they can be more readily 'checked' than other forms of contraception. They are clinic-based and require the involvement of more than one provider. In a bureaucracy where the potential for fake reporting is large and where supervisors must either rely on workers' reports or undertake extensive field checks, IUD and sterilisation cases are more readily subject to reliable verification than pill or condom use. Systematic field checks are not easy in a large and dispersed field programme, requiring a much stronger supervisory field presence in Bangladesh than was implemented even in areas where the programme received outside support. The emphasis on sterilisation and IUD targets as a performance measure also served the interests of supervisors whose commitment to more complex, field-based supervision was extremely weak.

Although injectables are also provider-controlled, when they are provided in the home they are less readily checked by supervisors and therefore of less interest to a bureaucratic system that has limited capacity to check work in a large field-based programme. Sterilisation and IUDs are also less costly than injectables or pills, especially if these methods are used for a long period of time.

In a more general sense, the target system functioned as a substitute for effective, supportive and problem solving supervision. Supervisors and higher level managers were not oriented towards providing the type of work environment which encourages field staff towards high standards of quality of care and performance more generally. Respondents consistently lamented the lack of support they received from supervisors: 
Worker: Sirs praise those who can show the highest contraceptive prevalence rate, but those who work hard but cannot produce the highest prevalence rate that is never seen by the Sirs. They never want to know what was the worker's problem and how to solve it.

Or:

Worker: If we request the Family Planning Inspector to show us the correct method of a work, then he does not give us necessary instructions, rather, he will say, 'Oh! You have been working for such a long time but don't know these things.' He will never explain anything. He is never helpful to our work.

Or:

Worker: If they threaten us and call us worthless in front of our clients, the clients will never listen to us. We become very sad when we get such behaviour from them. We have not told about this to anybody. If you go to a village and show me respect, then the women of that village will show more respect to me. They will then give more importance to what we tell them and that will be advantageous for the progress of our work. On the contrary, if you go to a village and start threatening us then the women will neither listen to us nor will they put any importance to what we say.... We may be subordinates but we also have our own dignity and self-respect.

In the field of management it has been consistently argued that 'to motivate the worker to peak performance, it is equally important that management set and enforce on itself high standards for its own performance of those functions that determine the worker's ability to perform' (Drucker 1968: 365). Such supportive and exemplary supervision, however, is not a strong point of the public sector family planning bureaucracy of Bangladesh. Supervision is predominantly punitive rather than problem solving in nature, and targets are used as a managerial short cut for effective supervision. More generally, female fieldworkers were often viewed as convenient subjects who could be blamed for programme failures: For example: 
Moderator: Do your supervisors give recognition to your official work?

Worker 1: They do not recognise our work at all. Their version is that FWAs do not work at all; all the work is done by them.

Worker 2: On the day of the meeting, they openly say that we do not do any work. If we do not work then how come the CPR [contraceptive prevalance rate] increases day by day?

Worker 1: They do not reply to our questions. If anyone of us protests, they become irritated.

Moderator: Do they not appreciate any of your good work?

Worker 3: No, we have never received any appreciation for our good deeds.

Worker 2: We pass the time before the arrival of our officer in a meeting in gossiping, when we feel peace. As soon as the officer arrives in the meeting our peace is disturbed. The meeting usually starts with discussions of the faults committed by FWAs, followed by threats and rebukes for FWAs. It appears that all the responsibilities lie with the FWAs.

Workers also were a readily available source from whom illicit payments could be extracted. Fieldworkers repeatedly reported that they were expected to make informal payments to their supervisors, other higher level officers, or office staff:

Worker 1: When we spend 100 Taka for the patient and submit a reimbursement voucher, ultimately I will get only 25 Taka.

Moderator: What happens with the rest of the 75 Taka?

Worker 1: The rest goes to the office personnel.

Worker 2: We have a lot of problems to get our money. We have to pay this one and that one to keep the work progressing so that we can get our money.

Worker 3: Listen to a story. I was trying to get a bill cleared and I had to give once 600 then again 500 to the officer. I asked the officer: 'Sir, why do you take so much?'. . . . See, among 3,000 Taka, I had to spend more than 1,000 Taka. I was so sad.

Above, we already discussed that supervisors withheld salaries to motivate workers to fulfil their targets. Closer analysis reveals that 
targets were used as a convenient pretext which allowed supervisors and officials to obtain illegal cuts from the workers salary. This is clearly articulated in the following two quotations:

Target is good as it increases the enthusiasm of a worker to do more work. But it is more used to take money from us.

\section{Or:}

When higher authority wants to have some money then they think of putting the pressure on targets.

The practice of extracting illegal payments was not limited to the family planning programme, nor was it a direct outgrowth of the target system. Demands for unofficial payments are a pervasive pattern in the bureaucracy in Bangladesh more generally, in part because salaries are extremely low. The quantitative acceptor targets contributed towards creating an organisational climate which readily lent itself to such unofficial resource extraction from fieldworkers. This system also created special vulnerabilities in a highly gender-biased organisational structure where women occupy the lowest rank in the hierarchy and their supervisors and officers are men. In providing a rationale for withholding workers' salaries, or issuing a 'show cause' notice, targets increased the need for these women to come to the subdistrict health complex to explain themselves to an officer. With greater need for such visits, fieldworkers' risk of sexual harassment, which was widely, though cautiously, discussed among respondents, increased. Their comments made clear that they felt a strong need to guard against visiting officers alone.

Targets should not be viewed as the cause of either the prevalent demand for illegal payments or of the considerable threat of sexual harassment. These practices existed independently from the system of quotas for contraceptive acceptors. However, by creating apparent justifications for withholding salaries and issuing 'show cause' notices, targets increased the worker's risk of becoming the victim of either one or both these practices. Women who occupied the lowest position in the occupational hierarchy of the family planning programme in a society where women's status is low, were thus jeopardised by 
targets in ways that are only apparent once these larger contextual managerial and social issues are considered.

\section{Conclusion: The Need for a Systems Change}

The target system established a deep-rooted set of motivations, providing the engine that drove the large government family planning programme in Bangladesh. As the above evidence has shown, the target system was closely linked to the structure of official and unofficial rewards, the pattern of supervision, the system of accountability, and a hierarchically organised and gender-biased organisational culture. Consequently, abolishing targets does not suffice to improve the quality of services.

When targets are removed but the rest of the management system remains unchanged, the family planning programme is left with the same dysfunctional organisational patterns that have generated many of the problem areas discussed in this paper. Where management practices are punitive, cooperative interaction and support are lacking. and fieldworkers are subject to wage extortion and sexual harassment, removal of family planning acceptor quotas are an insufficient remedy to move the programme to a greater level of quality of care. Policy decisions to remove targets certainly constitute an important initiative. However, this policy change must be accompanied by new directions for service delivery and management, including a new system of motivation and rewards, new values and patterns of accountability. Unless these underlying managerial determinants of quality of care are addressed, the hope for reaching ICPD goals will remain illusory.

\section{Notes}

1. The interviews were conducted at the project office at the subdistrict level by a moderator with extensive experience in group interviews. A detailed interview guideline was used. Interviews lasted between five and a half and seven hours, and included a lunch and other refreshments. Interviews were taped and subsequently translated into English and transcribed.

2. What we discuss here is the predominant pattern. There were also workers who reported that the pressure had lessened or was only periodically intense, and some did not mention these pressures at all. 


\section{References}

Bruce, Judith (1990). Fundamental elements of quality of care: A conceptual framework. Studies in Family Planning, 21(2), 61-91.

Drucker, Peter (1968). The practice of management. London: Pan.

Haaga, John G. and Rushikesh M. Maru (1996). The effects of operations research on program changes in Bangladesh. Studies in Family Planning, 27(2), 75-87.

Khallil, K. and C. Myntti (1994). Target-setting in family planning programs: Issues and controversies. Presented at the Population Council symposium on Family, Gender, and Population Policy: International Debates and Middle Eastern Realities, Cairo, Egypt, 7-9. February.

Phillips, James F., R. Simmons, G.B. Simmons and Md. Yunus (1984). Transferring health and family planning service innovations to the public sector: An experiment in organization development in Bangladesh. Studies in Family Planning, 15(5), 212-21.

Senge, Peter M. (1990). The fifth discipline: The art and practice of the learning organisation. New York: Doubleday.

Ward, Rinehart, Sharan Rudy and Megan Drennan (1998). GATHER guide to counseling: Population reports, Series J, No.48. Baltimore: Centre for Communication Programmes, The Johns Hopkins School of Public Health.

Ruth Simmons is at University of Michigan, School of Public Health, Department of Health Behaviour/Health Education, 1420 Washington Heights, Ann Arbor, MI 48109-2029, USA. Tel: 734-647-8840; Fax: 734-763-7379; e-mail: simmons @umich. edu

Laura Ghiron is also at University of Michigan, School of Public Health, Ann Arbor, USA. E-mail: lighiron@umich.edu 